\title{
PERBEDAAN INDIKATOR-INDIKATOR OBESITAS PADA LANSIA HIPERTENSI DAN NON-HIPERTENSI
}

\author{
DIFFERENCES IN OBESITY INDICATORS BETWEEN HYPERTENSIVE AND \\ NON- HYPERTENSIVE ELDERLIES
}

\author{
Nur Lathifah Mardiyati ${ }^{1}$, Yuriza Agustin ${ }^{2}$ \\ ${ }^{1-2}$ Program Studi Ilmu Gizi, Fakultas Ilmu Kesehatan, Universitas Muhammadiyah Surakarta \\ Email Korespondensi : nlm233@ums.ac.id
}

\begin{abstract}
Abstrak
Banyak kejadian hipertensi yang tidak terdiagnosa dikarenakan tidak munculnya tanda dan gejala sehingga diperlukan cara penentuan peningkatan risiko hipertensi yang lebih mudah teramati, seperti dari peningkatan IMT, lingkar pinggang (LP) dan rasio lingkar pinggang-panggul (RLPP) yang juga sebagai langkah promosi kesehatan untuk mencegah peningkatan kasus hipertensi dari diri sendiri. Penelitian ini merupakan penelitian observasional dengan rancangan cross-sectional yang dilaksanakan di Posyandu Lansia di Desa Bolon, Kecamatan Colomadu dengan jumlah subjek 30 untuk masing-masing kelompok yang dipilih secara consecutive sampling. Uji perbedaan dilakukan dengan Independent T-test. Hasil penelitian menunjukkan lebih dari separuh responden yang non-hipertensi memiliki IMT, LP dan RLPP yang normal (70\%, 67\% dan 77\%) sedangkan untuk responden yang hipertensi sebagian besar memiliki status gizi lebih (63\%, 73\% dan 70\%). Walaupun lebih dari separuh responden yang hipertensi memiliki IMT lebih, dari uji Independent T-test tidak menunjukkan perbedaaan yang signifikan (nilai p> 0,05). Namun, untuk LP dan RLPP menunjukkan perbedaan yang signifikan antara respoden dengan hipertensi dan tidak hipertensi (nilai $\mathrm{p}<0,05$ ). Sehingga dapat disimpulkan bahwa terdapat perbedaan signifikan pada LP dan RLPP tetapi tidak dengan IMT pada lansia hipertensi dan yang tidak mengalami hipertensi. Hal ini menunjukkan bahwa penumpukan lemak di sekitar perut yang lebih mempengaruhi tekanan darah dibandingkan dengan IMT atau proporsi tubuh secara keseluruhan.
\end{abstract}

Kata Kunci : Lansia, hipertensi, lingkar pinggang, lingkar panggul, IMT

\begin{abstract}
Many incidents of hypertension are not diagnosed due to the absence of signs and symptoms. Thus, there is a need for a more easily observed increase in the risk of hypertension, such as changes in such as increased BMI, waist circumference (WC) and waist-to-hip ratio (WHR) which also as a self-care health promotion behaviour to prevent an increase of hypertension case. This study was an observational study with cross-sectional design conducted at Elderly Posyandu in Bolon, Colomadu District with the number of subjects was 30 for each group selected by consecutive sampling. Difference test was performed with Independent T-test. More than half of non-hypertensive respondents had normal BMI, WC and WHR $(70 \%$, 67\% and 77\%, respectively) while most hypertensive respondents had high nutritional status (63\%, 73\% and 70\%). Although more than half of respondents with hypertension had high BMI, the Independent T-test did not show a significant difference ( $p>0.05)$ while for WC and WHR showed significant differences $(p<0.05)$. So it can be concluded that there are significant differences in WC and WHR but not with BMI in hypertensive and non hypertensive elderlies. This suggests that the build up of fat around the abdomen is more affecting blood pressure than with BMI or the proportion of the body as a whole.
\end{abstract}

Keywords: Elderly, hypertension, waist circumference, hip circumference, BMI 


\section{PENDAHULUAN}

Hipertensi atau kenaikan tekanan darah merupakan penyebab penyakit jantung iskemik dan stroke1 yang merupakan dua penyebab kematian tertinggi menurut WHO.2 Berdasarkan data Riskesdas, pravelensi hipertensi juga mengalami peningkatan dari $7,6 \%$ di tahun 2007 menjadi 9,5\% di tahun 2013. ${ }^{3}$

Sayangnya, banyak kejadian hipertensi yang tidak terdiagnosa salah satunya dikarenakan tidak munculnya tanda dan gejala.1 Pemantauan tekanan darah yang merupakan langkah promosi kesehatan dari diri sendiri yang utama pun sulit untuk diamati. Padahal mengetahui status kesehatan dan risiko terhadap penyakit merupakan langkah pertama dari promosi kesehatan dari diri sendiri untuk penyakit jantung. ${ }^{4}$ Sehingga diperlukan cara penentuan peningkatan risiko yang lebih mudah teramati, seperti dari perubahan ukuran antropometri tubuh. Dari beberapa penelitian juga diketahui bahwa tekanan darah diketahui berhubungan dengan IMT, lingkar pinggang dan rasio lingkar pinggang-panggul (RLPP). ${ }^{5-11}$ Peningkatan IMT, lingkar pinggang dan RLPP yang melebihi nilai normal diketahui dapat meningkatkan angka mortalitas ${ }^{12}$ dan morbiditas ${ }^{13}$ beberapa penyakit degeneratif seperti diabetes mellitus, kanker termasuk hipertensi. Apabila peningkatan risiko dapat teramati oleh diri sendiri lebih dini, penanganan lebih lanjut dapat dilakukan segera sehingga diharapkan dapat membantu mengontrol atau bahkan menurunkan prevalensi hipertensi. Mengingat langkah dari diri sendiri ini sangat penting dalam promosi kesehatan dan pencegahan penyakit. ${ }^{4}$ Oleh karena itu, penelitian ini dilakukan untuk melihat signifikasi perbedaan IMT, lingkar pinggang dan RLPP pada lansia yang hipertensi dan tidak hipertensi.

\section{METODE}

Penelitian ini merupakan penelitian observasional dengan rancangan cross-sectional yang dilaksanakan di lokasi kegiatan Posyandu Lansia di Desa Bolon, Kecamatan Colomadu pada bulan Juli 2017. Populasi dalam penelitian ini adalah semua lansia yang tercatat sebagai penduduk di Desa Bolon dan terdaftar sebagai anggota posyandu lanjut usia. Adapun besar sampel penelitian yaitu sebesar 30 subjek untuk masing-masing kelompok sehingga dari populasi terjangkau tersebut dipilih 60 orang secara consecutive sampling sebagai sampel dengan perbandingan $1: 1$, dengan kriteria sampel yaitu berusia $\geq 45$ tahun, dapat berdiri tegak (tidak bungkuk), dan tidak mempunyai penyakit yang dapat mempengaruhi tekanan darah. Responden tidak akan dijadikan sebagai subjek penelitian bila mengalami asites, edema extremitas, hepatomegali (pembesaran hati), splenomegali (pembesaran limfa) atau sedang menjalani diet tertentu.

Identitas sampel yang dicatat meliputi nama, umur dan jenis kelamin yang didapatkan dari buku register yang ada di posyandu lansia dan wawancara secara langsung. Berat badan diukur dengan menggunakan timbangan injak kapasitas $130 \mathrm{~kg}$, ketelitian $0,1 \mathrm{~kg}$. Tinggi badan diukur menggunakan microtoice, kapasitas 200 $\mathrm{cm}$, ketelitian $0,1 \mathrm{~cm}$. Lingkar pinggang dan RLPP di- peroleh dengan menggunakan pita ukur, kapasitas 150 $\mathrm{cm}$ dengan ketelitian $0,1 \mathrm{~cm}$. Untuk tabu silang, lingkar pinggang dikategorikan lebih bila $>80 \mathrm{~cm}$ untuk perempuan dan $>90 \mathrm{~cm}$ untuk laki-laki. Sedangkan untuk RLPP, dikatakan lebih bila $\leq 0,90$ dan wanita $\leq 0,77.14$ Tekanan darah sistolik dan diastolik diperoleh dengan menggunakan sphigmomanometer yang dibantu oleh mahasiswa keperawatan dinyatakan dalam satuan $\mathrm{mmHg}$. Diagnosis hipertensi atau tidak hipertensi ditentukan oleh dokter. Subjek dikatakan hipertensi bila tekanan darahnya $>140 / 90 \mathrm{mmHg}$ untuk yang berusia $<60$ tahun dan $>150 / 90 \mathrm{mmHg}$ bila usia $>60$ tahun. 15 Nama obat dan waktu terakhir dikonsumsi dicatat. Bila obat terakhir dikonsumsi masih dalam durasi efektif obat, maka responden dikeluarkan dari sampel karena dikhawatirkan efek antihipertensi dari obat mempengaruhi tekanan darah. Penelitian ini telah dinyatakan memenuhi kode etik dari Komite Etik Fakultas Kedokteran Universitas Muhammadiyah Surakarta.

Analisis data dilakukan dengan cara mentabulasikan nilai mean, median, standar deviasi, nilai maksimum dan nilai minimum dari variabel umur, IMT, lingkar pinggang, RLPP, dan tekanan darah. Analisisi bivariat dilakukan untuk menguji perbedaan IMT, lingkar pinggang dan RLPP antara lansia yang hipertensi dengan yang non-hipertensi. Uji Kolmogorov-Smirnov dilakukan untuk menguji kenormalan distribusi data dan semua variabel dinyatakan terdistribusi normal. Uji perbedaan menggunakan Independent T-test dengan tingkat kemaknaan nilai $p=0,05$. Jika nilai $p=\leq 0,05$ berarti terdapat perbedaan signifikan pada lansia hipertensi dan non-hipertensi.

\section{HASIL}

Karakteristik responden seperti yang tercantum pada Tabel 1 menunjukkan bahwa sebagian besar responden baik yang hipertensi maupun tidak hipertensi berusia antara 60-74 tahun dan berjenis kelamin perempuan. Lebih dari separuh responden yang nonhipertensi memiliki nilai IMT normal $(70 \%)$ sedangkan untuk responden yang hipertensi sebagian besar memiliki IMT lebih (63\%). Untuk lingkar pinggang dan RLPP menunjukkan hasil serupa yaitu sebagian besar

Tabel 1. Karakteristik Responden berdasarkan Tekanan Darah

\begin{tabular}{llcccc}
\hline & & \multicolumn{4}{c}{ Tekanan Darah } \\
& & & & & Hipertensi \\
\cline { 3 - 6 } & & Jumlah & $\mathbf{( \% )}$ & Jumlah & $\mathbf{( \% )}$ \\
& & & & & \\
\hline \multirow{2}{*}{ Usia } & $45-59$ & 10 & 33 & 10 & 33 \\
& $60-74$ & 18 & 60 & 15 & 50 \\
Jenis & $75-90$ & 2 & 7 & 5 & 17 \\
Kelamin & Laki-laki & 1 & 3 & 3 & 10 \\
& Perempuan & 29 & 97 & 27 & 90 \\
IMT & & & & & \\
\multirow{4}{*}{ Lingkar } & Kurang & 1 & 3 & 3 & 10 \\
Pinggang & Normal & 21 & 70 & 8 & 27 \\
RLPP & Lebih & 8 & 27 & 19 & 63 \\
& Lebih & 22 & 73 & 10 & 33 \\
& Normal & 8 & 27 & 20 & 67 \\
& Lebih & 21 & 70 & 7 & 23 \\
\hline
\end{tabular}

Sumber: Data Primer, 2017 
respoden yang hipertensi memiliki nilai yang lingkar pinggang dan RLPP yang lebih yaitu sebesar $67 \%$ dan $77 \%$ serta yang tidak hipertensi memiliki nilai lingkar pinggang dan RLPP yang normal (73\% dan 70\%).

Tabel 2. Uji Perbedaan IMT, Lingkar Pinggang dan RLPP berdasarkan Tekanan Darah

\begin{tabular}{llllll}
\hline & & Minimal & Maksimal & \pm SD & $\begin{array}{c}\text { Nilai } \\
\mathbf{p}\end{array}$ \\
\hline \multirow{2}{*}{ IMT } & Normal & 17,56 & 34,96 & $23,83 \pm 3.9$ & \\
& Hiperte & 17,07 & 35,00 & $25,7 \pm 4,80$ & 0,459 \\
& nsi & & & $75,77 \pm 11$, & \\
Lingkar & Normal & 54 & 103 & 81 & 0,037 \\
Pinggang & Hiperte & 52 & 102,5 & $82,93 \pm 14$, & $*$ \\
& nsi & & & 1 & \\
\multirow{2}{*}{ RLPP } & Normal & 0,72 & 0,98 & $0,79 \pm 0,09$ & 0,000 \\
& Hiperte & 0,62 & 1,27 & $0,90 \pm 0,11$ & $*$ \\
\hline
\end{tabular}

Sumber: Data Primer, 2017

Untuk menguji perbedaan dilakukan uji Independet T-test dengan hasil seperti pada Tabel 2 yang menunjukkan hasil yang sedikit berbeda. Uji perbedaan nilai IMT antar kedua kelompok menunjukkan nilai $\mathrm{p}$ di atas 0,05 yaitu 0,459 sedangkan untuk lingkar pinggang dan RLPP menunjukkan nilai $\mathrm{P}$ di bawah 0 , 05 yaitu 0,037 dan 0,000 .

\section{PEMBAHASAN}

Pada penelitian ini melihat perbedaan indikatorindikator kegemukan pada lansia hipertensi dan tidak hipertensi. Indikator-indikator yang dianalisis perbedaannya yaitu indeks massa tubuh (IMT), lingkar pinggang, dan rasio lingkar-pinggang panggul (RLPP).

Hasil penelitian menunjukkan lebih dari separuh responden yang non-hipertensi memiliki IMT, lingkar pinggang dan RLPP yang normal $(70 \%, 67 \%$ dan $77 \%)$ sedangkan untuk responden yang hipertensi sebagian besar menunjukkan nilai lebih $(63 \%, 73 \%$ dan $70 \%)$. Walaupun sebagian besar responden yang hipertensi memiliki IMT lebih, dari uji Independent T-test tidak menunjukkan perbedaaan yang signifikan antara kelompok hipertensi dengan yang tidak hipertensi (nilai $\mathrm{p}>$ $0,05)$ dimana kurang sejalan dengan penelitianpenelitian sebelumnya yang melihat nilai IMT dengan tekanan darah. ${ }^{8,9,15,16}$ Namun, untuk lingkar pinggang dan RLPP menunjukkan perbedaan yang signifikan antara respoden dengan hipertensi dan tidak hipertensi (nilai $\mathrm{p}<0,05)$ dan sejalan dengan penelitian-penelitian sebelumnya. $^{5-7}$

Hasil ini cukup menarik mengingat yang mempengaruhi tekanan darah bukan karena kelebihan lemak tetapi lebih ke lokasi penumpukan lemak itu sendiri. Penumpukan lemak di sekitar perut yang akan meningkatkan tekanan darah. Hasil ini sejalan dengan penelitian cohort di Brazil yang juga menunjukkan bahwa tingginya tekanan darah dapat diidentifikasi secara lebih baik dari peningkatan lingkar pinggang dibandingkan dari pengukuran IMT. ${ }^{11}$ Suatu penelitian meta analisis dari 10 penelitian dengan subjek penelitian dari berbagai etnis dan range usia juga menunjukkan bahwa adanya obesitas abdominal lebih dapat menunjukan peningkatan risiko penyakit kardivaskuler yang lebih baik dibandingkan dengan obesitas secara keseluruhan atau dalam hal ini dilihat berdasarkan dari nilai IMT. ${ }^{18}$

Dalam penelitian ini, lingkar pinggang merupakan indikator obesitas yang paling mudah diukur mengingat hanya perlu dilakukan satu jenis pengukuran dibandingkan IMT atau RLPP yang perlu dilakukan 2 jenis pengukuran (tinggi dan berat badan atau lingkar pinggang dan lingkar panggul). Selain itu, hasilnya pun tetap dapat menunjukkan perbedaan yang signifikan antara lansia yang hipertensi dan tidak hipertensi sama seperti dari pengukuran RLPP bahkan lebih bisa menunjukkan perbedaan dibandingkan dengan pengukuran IMT saja.

Terlepas dari hasil penelitian ini yang masih mendukung beberapa penelitian-penelitian sebelumnya, penelitian ini masih memiliki keterbatasan yaitu kecilnya jumlah subjek penelitian dan tidak dianalisis secara terpisah antara subjek laki-laki dan perempuan yang di beberapa penelitian menunjukkan sedikit perbedaan hasil di antara kedua jenis kelamin. ${ }^{11,17-19}$

\section{KESIMPULAN}

Penelitian ini menyimpulkan bahwa terdapat perbedaan signifikan pada lingkar pinggang dan rasio lingkar pinggang dan panggul (RLPP) tetapi tidak dengan indeks masa tubuh (IMT) pada lansia hipertensi dan yang tidak mengalami hipertensi. Hal ini menunjukkan bahwa penumpukan lemak di sekitar perut yang lebih mempengaruhi tekanan darah dibandingkan dengan IMT atau proporsi tubuh secara keseluruhan. Sehingga langkah promosi kesehatan untuk menghindari peningkatan prevalensi hipertensi, khususnya pada lansia, dapat dilakukan salah satunya dengan menyampaikan kepada para lansia dengan lingkar pinggang dan RLPP yang besar, perlu mewaspadai risiko peningkatan tekanan darah agar dapat segera mendapatkan penanganan lebih lanjut.

\section{UCAPAN TERIMA KASIH}

Ucapan terima kasih disampaikan kepada dr. Listiana Dharmawati S, M.Si. atas masukan yang membangun untuk penelitian ini.

\section{DAFTAR PUSTAKA}

1. WHO. WHO | A Global Brief on Hypertension. World Health Organization; 2013. http:// www.who.int/cardiovascular_diseases/publications/ global_brief_hypertension/en/. Accessed November 24, $20 \overline{1} 7$.

2. WHO. WHO $\mid$ The Top 10 Causes of Death. World Health Organization; 2017. http:/www.who.int/ mediacentre/factsheets/fs310/en/. Accessed November 24, 2017.

3. Badan Penelitian dan Pengembangan Kesehatan. Riset Kesehatan Dasar (RISKESDAS) 2013.; 2013. doi:1 Desember 2013.

4. Riegel B, Moser DK, Buck HG, et al. Self-Care for the Prevention and Management of Cardiovascular Disease and Stroke. J Am Heart Assoc. 2017;6 
(9):e006997. doi:10.1161/JAHA.117.006997.

5. Kartika RD. Hubungan Indikator Obesitas Abdominal Dengan Tekanan Darah. 2008. http:// eprints.undip.ac.id/26054/. Accessed November 27, 2017.

6. Oviyanti PN. Hubungan antara Lingkar Pinggang dan Rasio Lingkar Pinggang Pangul dengan Tekanan Darah pada Dewasa. 2010. https:// eprints.uns.ac.id/10863/. Accessed November 27, 2017.

7. Ernitasari PD, Djarwoto B, Siswati T. Pola makan, rasio lingkar pinggang pinggul (RLPP) dan tekanan darah di Puskesmas Mergangsan Yogyakarta. J Gizi Klin Indones. 2009;6(2):71-77. doi:10.22146/ IJCN.17714.

8. Widyastuti N. Hubungan beberapa Indikator Obesitas dengan Hipertensi pada Perempuan. 2005. http:// eprints.undip.ac.id/26179/. Accessed November 27, 2017.

9. Sumayku IM, Pandelaki K, Wongkar MCP. Hubungan Indeks Massa Tubuh dan Lingkar Pinggang dengan Tekanan Darah pada Mahasiswa Fakultas Kedokteran Universitas Sam Ratulangi. e-CliniC. 2014;2(2). https://ejournal.unsrat.ac.id/index.php/ eclinic/article/view/5022. Accessed November 27, 2017.

10. Dien NG, Mulyadi N, Kundre R. Hubungan Indeks Massa Tubuh (IMT) dengan Tekanan Darah pada Penderita Hipertensi di Poliklinik Hipertensi dan Nefrologi BLU RSUP Prof.DR. R. D. Kandau Manado. J KEPERAWATAN. 2014;2(2). https:// ejournal.unsrat.ac.id/index.php/jkp/article/ view/5168. Accessed November 27, 2017.

11. Gus M, Fuchs SC, Moreira LB, et al. Association between different measurements of obesity and the incidence of hypertension. Am J Hypertens. 2004;17(1):50-53. doi:10.1016/ j.amjhyper.2003.08.010.

12. Flegal KM, Kit BK, Orpana H, Graubard BI. Association of All-Cause Mortality With Overweight and Obesity Using Standard Body Mass Index Categories. JAMA. 2013;309(1):71. doi:10.1001/ jama.2012.113905.

13. Nyamdorj R. BMI Compared With Central Obesity Indicators in Relation to Diabetes and Hypertension in Asians. Obesity. 2008;16(7):1622-1635. doi:10.1038/oby.2008.73.

14. Anggraeni AC. Asuhan Gizi Nutritional Care Process. Yogyakarta: Graha Ilmu; 2012.

15. James PA, Oparil S, Carter BL, et al. 2014 Evidence-Based Guideline for the Management of High Blood Pressure in Adults. JAMA. 2014;311(5):507. doi:10.1001/jama.2013.284427.

16. Astuti AAAFD, Widyastuti N, Kusumastuti AC. Hubungan Beberapa Indikator Obesitas dengan Tekanan Darah Wanita Dewasa Muda. J Nutr Coll. 2017;6(3):219-225. http://ejournal3.undip.ac.id/ index.php/jnc/article/view/16913/17264. Accessed November 25, 2017.

17. Fauziana R, Jeyagurunathan A, Abdin E, et al. Body mass index, waist-hip ratio and risk of chronic med- ical condition in the elderly population: results from the Well-being of the Singapore Elderly (WiSE) Study. BMC Geriatr. 2016;16(1):125. doi:10.1186/ s12877-016-0297-z.

18. Lee CMY, Huxley RR, Wildman RP, Woodward M. Indices of abdominal obesity are better discriminators of cardiovascular risk factors than BMI: a metaanalysis. J Clin Epidemiol. 2008;61(7):646-653. doi:10.1016/j.jclinepi.2007.08.012.

19. Li W-C, Chen I-C, Chang Y-C, Loke S-S, Wang S$\mathrm{H}$, Hsiao K-Y. Waist-to-height ratio, waist circumference, and body mass index as indices of cardiometabolic risk among 36,642 Taiwanese adults. Eur J Nutr. 2013;52(1):57-65. doi:10.1007/s00394011-0286-0.

\section{Submit your next manuscript to MPPKI}

- We accept pre-submission inquiries

- Our selector tool helps you to find the most relevant journal

- We provide round the clock customer support

- Convenient online submission

- Maximum visibility for your research

Submit your manuscript at http://jurnal.unismuhpalu.ac.id/index.php/MPPKI/ index

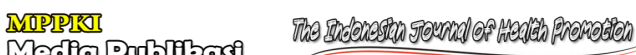

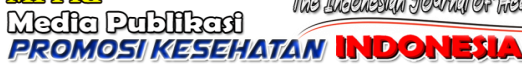

